\title{
Effect of Alloying Elements on Fracture Toughness and Ductility in Magnesium Binary Alloys; A Review*1
}

\author{
Hidetoshi Somekawa*2 \\ Research Center for Structural Materials, National Institute for Materials Science, Tsukuba 305-0047, Japan
}

The development of magnesium alloys, which exhibit high strength and high ductility (fracture toughness), is critical for ensuring the safety and reliability in structural applications. It is well-known that grain refinement and/or alloying are impressive strategies to attain such properties in metallic materials. In the former case, grain boundaries of magnesium and its alloys have unique characteristics, e.g., sites for nonbasal dislocation activity and occurrence of partial grain boundary sliding. As a result, strength as well as ductility (fracture toughness) tend to increase and improve with grain refinement. In the latter case, 29 types of solid solution elements, which have a maximum solubility of more than 0.1 at $\%$, can dissolve in magnesium. Several elements are generally added to magnesium simultaneously to achieve good mechanical properties via a synergistic effect. In industrial fields, ternary magnesium alloys such as $\mathrm{Mg}-\mathrm{Al}-\mathrm{Zn}$ and $\mathrm{Mg}-\mathrm{Zn}-\mathrm{Zr}$ alloys, which have finegrained structures, have been widely used; however, there is no still clear and systematic understanding of the impact of various alloying elements on properties for magnesium. In this paper, we review recent studies on the effect of solid solution alloying elements on ductility (fracture toughness), with focusing on polycrystalline binary magnesium alloys. With regard to the toughness, the crack-propagation behavior and/or fracture behavior are quite sensitive to the alloying element, regardless of grain size. Twin boundaries in particular are recognized as harmful defects, because they act as crack-propagation sites. Nevertheless, changing the electric bonding behavior through alloying has the potential to increase the toughness. As for the ductility, the alloying elements also dramatically affect the room-temperature plastic deformation. In addition to the activation of the non-basal dislocation slip, grain boundary sliding also plays a notable role in enhancing the elongation-tofailure in tension. [doi:10.2320/matertrans.MT-M2019185]

(Received July 5, 2019; Accepted August 16, 2019; Published September 30, 2019)

Keywords: magnesium, mechanical properties, grain boundary plasticity, solute elements, deformation mechanism

\section{Introduction}

Magnesium was first isolated in pure form by Humphry Davy in 1808 (it has also been claimed that this discovery was first made by Joseph Black in 1755). Unlike steel, which has been widely used in daily life for millennia, this metal of magnesium has a relatively new and short history. The amount of demand and production of magnesium was small after its discovery, but usage and consumption of magnesium sharply increased during the two world wars. In the 1950s and 1960s, a lot of researchers conducted intensive basic investigations using single crystals, which led to a detailed understanding of the crystal plasticity of magnesium. ${ }^{1-11)}$ Recently, magnesium, which is a material that can potentially be used in solving severe global environmental issues, has attracted significant attention as a next-generation lightweight metal, because it has the lowest density among the conventional metallic materials. As an example, when the structure and/or components of motor vehicles enable a weight reduction of $100 \mathrm{~kg}$, the improvement in fuel efficiency is estimated to be $0.9 \mathrm{~km} / \mathrm{L}^{12)}$ Efforts into achieving such a significant weight reduction can benefit from applying magnesium to both existing and new components and/or parts. Thus, the use of magnesium and its alloys has been attempted not only in vehicles but also in other applications, such as electronics and medical equipment.

The mechanical properties of materials used in structural applications must satisfy both the reliability and safety requirements. Specifically, there is strong demand for developing materials that exhibit good properties of strength

\footnotetext{
${ }^{* 1}$ This Paper was Originally Published in Japanese in J. Japan Inst. Met. Mater. 83 (2019) 65-75.

${ }^{* 2}$ Corresponding author, E-mail: SOMEKAWA.Hidetoshi@nims.go.jp
}

and ductility/toughness. The alloying process, wherein one or more elements are added to a pure metal, has been used to improve these mechanical properties of magnesium as well as other metallic materials. Figure 1 shows the periodic table including notes regarding the atomic radius and maximum solubility (chemical composition) in magnesium. The solute element shaded with gray color in this figure indicates that the maximum solubility is more than 0.1 at\%. ${ }^{13-15)}$ Each of 29 elements (only 14 elements, if rare-earth (RE) elements are excluded) is found to be soluble in magnesium. Suitable combinations of alloying elements and their chemical compositions have been examined to improve various properties including strength and ductility/toughness. From the standpoints of cost and manufactural handling, aluminum and zinc are the preferred alloying elements, since these elements are inexpensive and are highly soluble into magnesium. The $\mathrm{Mg}-\mathrm{Al}-\mathrm{Mn}$ and $\mathrm{Mg}-\mathrm{Zn}-\mathrm{Zr}$ system alloys have been widely used, and the $\mathrm{Mg}-\mathrm{Al}-\mathrm{Zn}$ system alloys are the most known and have the most applications of the magnesium alloys. Furthermore, the Mg-RE system alloys have been focused and studied, because their heat resistance improves through alloying with RE elements. ${ }^{16)}$ More interestingly, the $\mathrm{Mg}-\mathrm{RE}-\mathrm{Zn}$ alloys that include the ordered structures, such as the long periodic stacking ordered structures, were developed in the early 21 th century in Japan. This alloy has attracted significant interest worldwide, owing to its properties of high strength and good flame resistance. ${ }^{17,18)}$

With regard to the alloying method, understanding the impact and role of each solute element is important for determining a suitable alloying element, which plays a great role in improving the mechanical properties. Conventional and common metallurgical strategies, i.e., alloying and grain refinement, are well recognized as the efficiency to be 

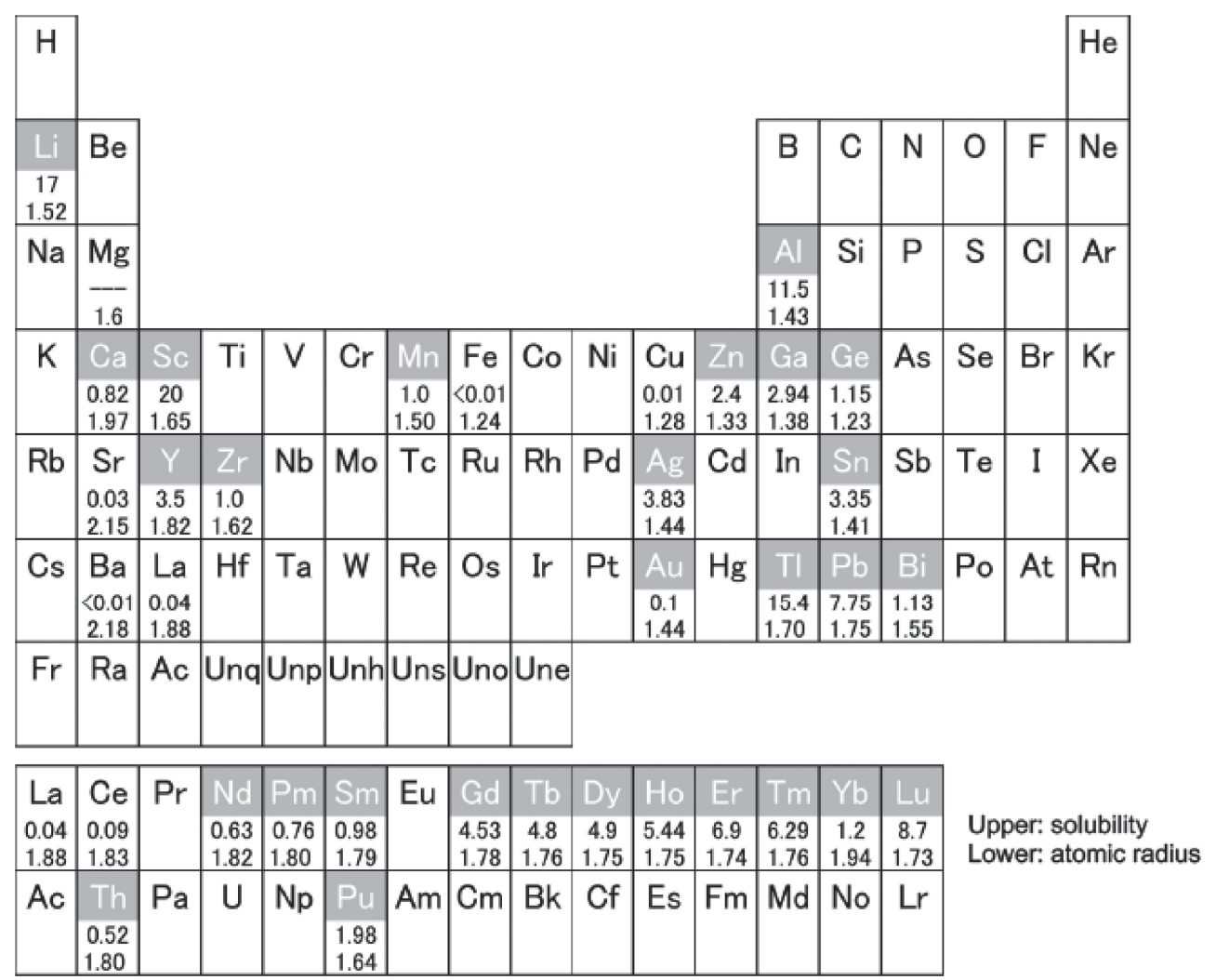

Fig. 1 The periodic table indicating maximum solubility (mol\%) to magnesium and atomic radius $\left(\times 10^{-10} \mathrm{~m}\right) .{ }^{13-15)}$ No value, i.e., a blank, indicates no data and/or no records in references and books.

strengthen in magnesium and its alloy. Needless to say, these two methods have been commonly applied to other metallic materials. Current numerical studies have predicted the most suitable alloying element with outstanding ability to strengthen, based on the elastic dislocation theory or the interaction model between the dislocations and the solute elements. ${ }^{19-23)}$ In contrast, the properties of ductility and toughness are associated both with the elastic and plastic deformation behaviors. The majority of common/conventional metallic materials are also bulked polycrystals containing numerous grains and grain boundaries. Therefore, there exist various influential factors and a considerable amount of parameters in polycrystalline metallic materials. Research into the best approach toward enhancing the properties of ductility and toughness has been ongoing not only for magnesium but also for other metallic materials. In this review, we outline the impact/role of the alloying element on the properties of toughness and ductility, focusing on the polycrystalline binary magnesium alloys reported in various recent papers.

\section{Toughness vs. Solid Solution Element}

\subsection{Fine-grained magnesium alloys}

The relationship between specific strength (= yield strength divided by density) vs. fracture toughness of magnesium alloys and aluminum alloys ${ }^{24)}$ is shown in Fig. 2. This figure shows that the specific strength of magnesium alloys is similar to that of aluminum alloys. Nevertheless, the fracture toughness of magnesium alloys is as about half levels as that of comparative alloys. It is also

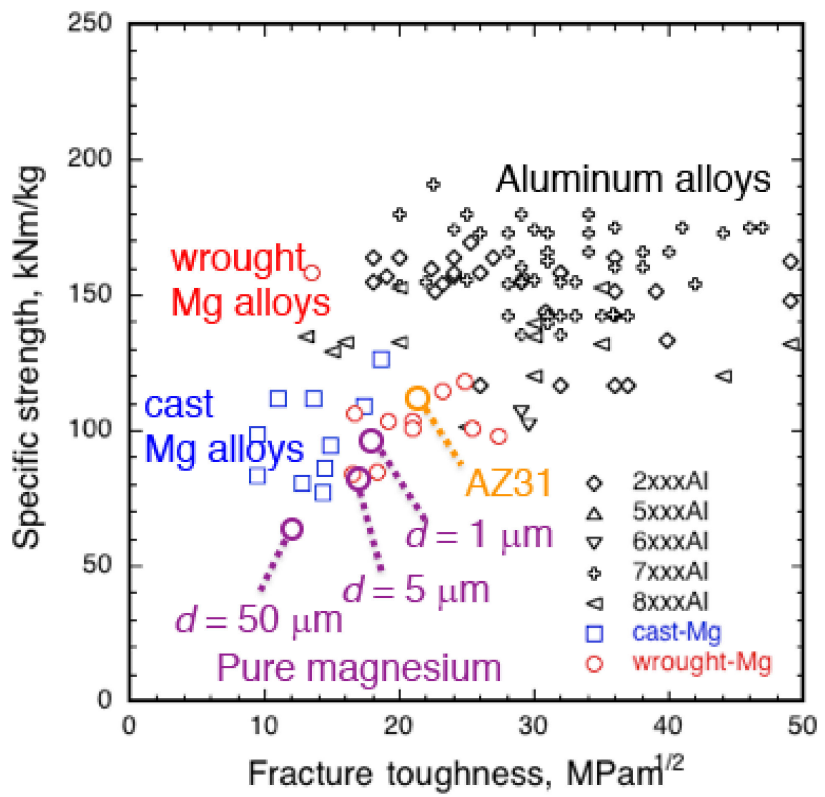

Fig. 2 Relationship between specific strength (= yield strength/density) and fracture toughness of conventional magnesium alloys and aluminum alloys. This figure also includes the results of magnesium having different grain sizes and AZ31 alloy. This figure is reconstructed in part from Ref. 24) with permission from JIM.

noted that wrought processed magnesium alloys exhibit higher fracture toughness as compared to that of cast processed magnesium alloys. Since the wrought process induces fine- and uniform-grained structures, the microstructural control is found to be an effective method of 
improving the fracture toughness. Figure 2 includes the mechanical properties in three types of extruded magnesium with different average grain sizes. The strength and fracture toughness tends to increase with grain refinement, due to the room-temperature plastic deformation related to the grain sizes. For magnesium, it is well known that deformation twinning forms to compensate for the lack of slip systems at room-temperature. However, the interface between deformation twinning and the matrix becomes a site for micro-voids and micro-cracks, because these interfaces have geometrical steps and gaps. ${ }^{25,26)}$ It has been reported that the vicinity of such an interface between deformation twinning and the matrix becomes the crack-propagation route during fracture toughness testing such as a introduction of a sharp crack into the specimens. ${ }^{27,28)}$ Thus, the presence of deformation twinning is not usually conducive to the continuation of further plastic deformation. There are recent several studies as for the plastic deformation of polycrystalline magnesium and its alloys. ${ }^{29-36)}$ They say that grain refinement leads to the activation of grain boundary plasticity, e.g., the activation of non-basal dislocation slips ${ }^{29}$ ) and the occurrence of partial room-temperature grain boundary sliding. ${ }^{30)}$ In addition, grain boundaries are closely related to deformation twinning. For instance, (i) grain boundaries become the nucleation or formation sites for deformation twinning ${ }^{31,32)}$ and (ii) the stress involved in forming the deformation twinning obeys the Hall-Petch relation. ${ }^{33-36)}$ Grain refinement (up to several microns in size) is an effective method to prevent the formation of deformation twinning, which is a harmful factor as mentioned above. Therefore, it can be said that this microstructural control, i.e., grain refinement, brings about attaining high fracture toughness in magnesium and its alloys.

Figure 2 also reveals that conventional extruded magnesium alloy (Mg-3Al-1Zn; AZ31 alloy) with an average grain size of $15 \mu \mathrm{m}$ exhibits superior characteristics compared with those of extruded magnesium. This result indicates that, in addition to microstructural control, alloying (selection of a suitable alloying element) has the possibility to enhance the fracture toughness. Figure 3 shows the fracture toughness of an extruded binary alloy with an average grain size of $\sim 3 \mu \mathrm{m}$.

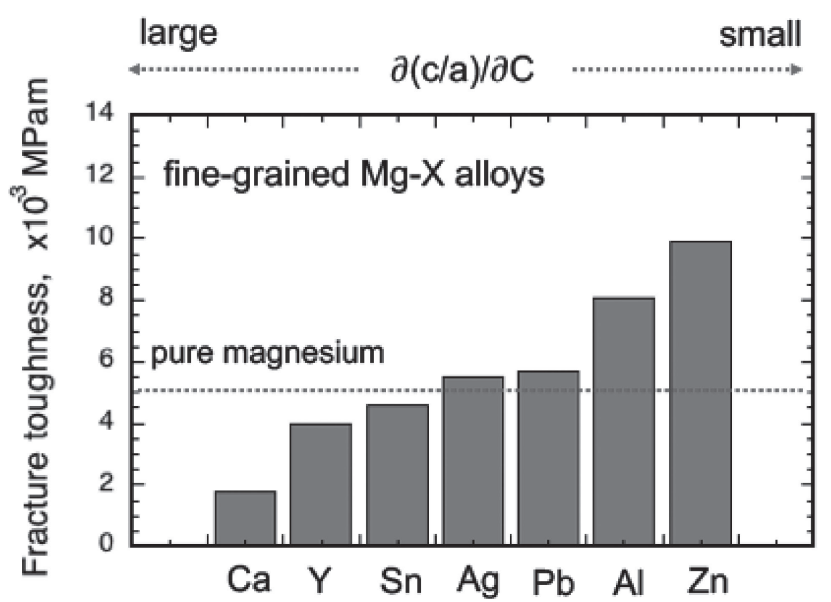

Fig. 3 Fracture toughness obtaining from fine-grained magnesium binary alloys. ${ }^{38)}$ The value of $\partial(c / a) / \partial C$ indicates the change in lattice parameter $c / a$ ratio with solute concentration in each element. ${ }^{52,53)}$
Alloying elements are apparently found to affect the fracture toughness of magnesium alloys. While the fracture toughness is closely related to the area and volume fraction of deformation twinning, the results presented in Fig. 3 are obtained from fine-grained binary alloys. As a result, the microstructural feature for deformation twinning is unlikely to be the influential factor, because a dense grain boundary accelerates grain boundary plasticity. ${ }^{37)}$ The results via microstructural observations ${ }^{38)}$ reveal that the crack-propagation along the grain boundaries demonstrates a high fraction in $\mathrm{Mg}-\mathrm{Ca}$ alloy with lower fracture toughness. These fracture features are similar to those of embrittlement fracture in metallic materials. The same fracture and propagation behaviors have been also observed in in-situ transmission electron microscopy (TEM) observation using a Mg-Y alloy, which does not have a good property of toughness. ${ }^{39)}$ On the other hand, in the $\mathrm{Mg}-\mathrm{Al}$ and $\mathrm{Mg}-\mathrm{Zn}$ alloys with higher fracture toughness than that of magnesium, the crack does not propagate along the grain boundaries, but rather into the matrix (grain interior). The fracture feature of these alloys shows ductile-like behavior.

In general metallic materials, embrittlement fracture is considered to result from grain boundary segregation. ${ }^{40,41)}$ The segregation of alloying elements at grain boundaries has been observed in a variety of magnesium alloys. ${ }^{42-48)}$ In the experience rule, the misfit factor between solute and solvent elements (= difference in atomic radius) is well used as an influential parameter for grain boundary segregation. The solute elements, which have a large misfit factor, are likely to have characteristics for segregation at grain boundaries. ${ }^{49,50)}$ When this rule applies to the case of magnesium, the misfit parameter is estimated to be $-11 \%$ and $+11 \%$ for aluminum and yttrium elements, respectively. Although the absolute values of these elements are the same, the magnesium alloys being added to these elements exhibit different fracture toughness and fracture feature. This indicates that the misfit factor is not suitable to be the influential factor of segregation behavior in magnesium alloys. One of the reasons for these disagreements is the difference in the atomic radius between the pure state and the alloying state. For instance, aluminum and silver have approximately similar atomic radii of $0.143 \mathrm{~nm}$ and $0.144 \mathrm{~nm}$, as shown in Fig. 1; however, the volume misfits in the solid solution state are $-35.8 \%$ for $\mathrm{Mg}-$ $\mathrm{Al}$ and $-63.4 \%$ for $\mathrm{Mg}-\mathrm{Ag}$, respectively. ${ }^{51)}$

It is well known that the lattice spacing (the $a$ - and $c$-axes in the lattice constant) in the hexagonal closed packed (h.c.p) structure depends on the alloying element and chemical composition. ${ }^{52,53)}$ In this review, the value of $\partial(c / a) / \partial C$, which denotes the change in the lattice parameter ratio, is used as an alternative parameter and should be ignored/ normalized in determining the impact of the alloying element. Figure 3 indicates a clear relation between fracture toughness and the value of $\partial(c / a) / \partial C$ in magnesium binary alloys. Some alloying elements such as RE or calcium elements, which bring about a large change in the lattice parameter, do not substantially contribute toward the improvement of fracture toughness. These elements cause large lattice strain not only to the matrix but also in the vicinity of the grain boundaries; as a result, they play a role in accelerating the occurrence of intergranular fracture. On the contrary, since 

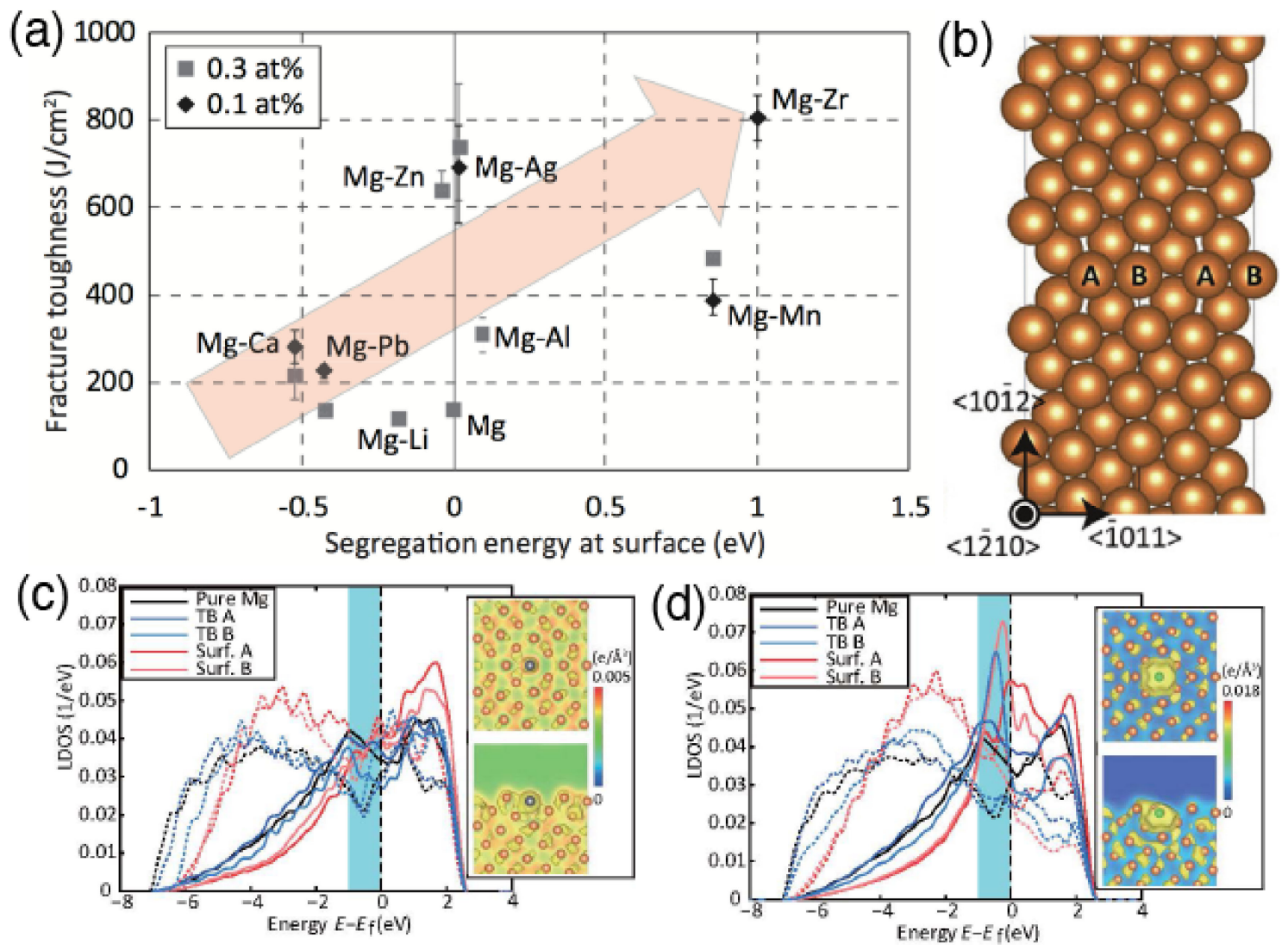

Fig. 4 (a) Surface segregation energy vs. fracture toughness obtaining from meso-grained magnesium binary alloys, (b) relaxed atomic configuration of the $\{10 \overline{1} 2\}$ twin boundary in first-principles calculation and partial charge density and LDOS of magnesium around (c) $\mathrm{Pb}$ and (d) $\mathrm{Zr}$ atom. LDOS of the partial density of states of the $s$ - (dashed lines) and $p$-band (solid lines) for compression A and expansion B sites as well as the perfect crystal, and partial charge density in the energy ranges -1 to $0 \mathrm{eV}$. This figure is reused in part of Ref. 66) with permission from Elsevier.

the lattice misfit is small in aluminum and zinc elements, adding these alloying elements helps to prevent such brittle fracture and to improve the fracture toughness. Instead of a simple explanation, the value of $\partial(c / a) / \partial C$ is one of the productive and judgmental parameters, whether or not the alloying is useful in enhancing the fracture toughness.

Lastly, as mentioned above, the calcium element causes grain boundary embrittlement in the binary alloy. However, it has been reported that this issue can be solved by adding other alloying elements and/or controlling the microstructure. Although the alloying for ternary and forth alloys is beyond the present topic, the combinational alloying of calcium and zinc elements, which changes the electrical bonding at grain boundaries, restrains grain boundary embrittlement. ${ }^{54)}$ Besides this method, controlling the grain boundary structure, which becomes the site for grain boundary segregation, is another effective strategy. Grain boundaries consisting of small free volumes, i.e., low-angle grain boundaries (misorientation angle of less than $15^{\circ}$ ), are difficult for the segregation sites as compared to conventional grain boundaries such as high-angle grain boundaries (misorientation angle of more than $15^{\circ}$ ). By using the recrystallization behavior through the thermomechanical process, magnesium alloys with a high fraction of lowangle grain boundaries exhibit good property of fracture toughness. ${ }^{55)}$

\subsection{Coarse/meso-grained magnesium alloys}

In the previous section, it is mentioned that preventing the formation and/or existence of deformation twinning is important for improving the fracture toughness of magnesium alloys. Here, this paper introduces a useful method for inhibiting and serious microstructures, that is, deformation twinning, to enhance the fracture toughness in coarse- and meso-grained alloys. Recent studies regarding the twining of magnesium have reported that an alloying element is likely to segregate at the twin boundaries, such as the $\{10 \overline{1} 2\}$ twin boundaries, under static annealing conditions. ${ }^{56)}$ These twin boundaries, where the alloying elements segregate, contribute toward acquiring high strength, ${ }^{56-58)}$ have a small movement with applied strain and affect the growth and shrink of the twin boundaries. ${ }^{59-62)}$ They also lead to change in the crackpropagation behavior. ${ }^{63-65)}$ Figure 4(a) shows the fracture toughness of twin-induced magnesium binary alloys with an average grain size of approximately $20 \mu \mathrm{m}$. Fracture toughness is not as high in value, because of the meso-grained structure and low chemical composition; on the other hands, the alloying element tends to be an influential factor. This alloying element effect is found to be similar to that exerted by fine-grained alloys, as shown in Fig. 3. Microstructural observations before and after bending tests have revealed that crack-propagation behavior depends on the alloying element. When comparing the deformed microstructural features of the $\mathrm{Mg}-\mathrm{Ag}$ and $\mathrm{Mg}-\mathrm{Li}$ alloys, the interface between the matrix 
and the twin boundaries of the $\mathrm{Mg}-\mathrm{Li}$ alloy becomes an easier crack propagation site than those of the $\mathrm{Mg}-\mathrm{Ag}$ alloy. From the concept of grain boundary cohesive energy based on the fracture mechanics model, fracture toughness and crack-propagation behavior are closely related to the change in grain boundary segregation energy vs. surface ( $=$ a newly formed surface due to crack propagation) segregation energy. The alloying element stabilizing the twin boundary energy, which means that it does not play a role in the stabilization of the surface energy, prevents crack-propagation along the interface between the matrix and the twin boundaries. ${ }^{66)}$

The $\mathrm{x}$-axis in Fig. 4(a) represents the surface segregation energy obtained from a first-principles calculation method in each alloying element. The alloy containing an element with large surface segregation energy shows high fracture toughness. The alloying element, which stabilizes the twin boundary energy rather than the surface energy, will obviously be more effective in increasing the fracture toughness. This trend is the same for the microstructural observation as for the crack-propagation behavior. Figure 4(c) and 4(d) are the local density of state (LDOS) and the electric density map around the alloying elements at the twin boundary and surface of the $\mathrm{Mg}-\mathrm{Pb}$ and $\mathrm{Mg}-\mathrm{Zr}$ models. In Fig. 4(b), the solute element locates the lowest energy among all positions at the vicinity of the $\{10 \overline{1} 2\}$ twin boundary in each alloying model. The LDOS map of the $\mathrm{Mg}-$ $\mathrm{Pb}$ model, where the lead element is unlikely to improve the fracture toughness, is similar to that of the base-state, i.e., magnesium. In addition, the LDOS and electric density maps of the twin boundary are noted to be similar to those of the surface. In contrast, these features of the $\mathrm{Mg}-\mathrm{Zr}$ model are different from those of the $\mathrm{Mg}-\mathrm{Pb}$ model and the models to which other alloying elements are added. The strong combination between the $d$-orbit and $p$-orbit is confirmed to form the $\mathrm{Mg}-\mathrm{Zr}$ model. As an example for comparison, the electric density map shows that the surface segregation of the $\mathrm{Mg}-\mathrm{Zr}$ model is quite different from those of magnesium and other alloying elements. ${ }^{66)}$ Even in coarse- and mesograined magnesium alloys, controlling the binding behavior via the alloying element can potentially ensure that such a twin boundary is not harmful but an impressive factor for enhancing the facture toughness.

\section{Ductility vs. Solid Solution Element}

\subsection{Deformation behavior into grains and at grain boundaries}

The relationship between the grain size and the elongationto-failure in tension of magnesium and its typical binary alloys is shown in Fig. 5. These plotted values are taken from tensile tests in quasi-static strain rate regimes $\left(10^{-2}\right.$ up to $10^{-4} / \mathrm{s}$ ) to eliminate the strain rate dependence. It is well known that the elongation-to-failure in tension of wrought processed (e.g., extrusion and rolling) magnesium alloys is

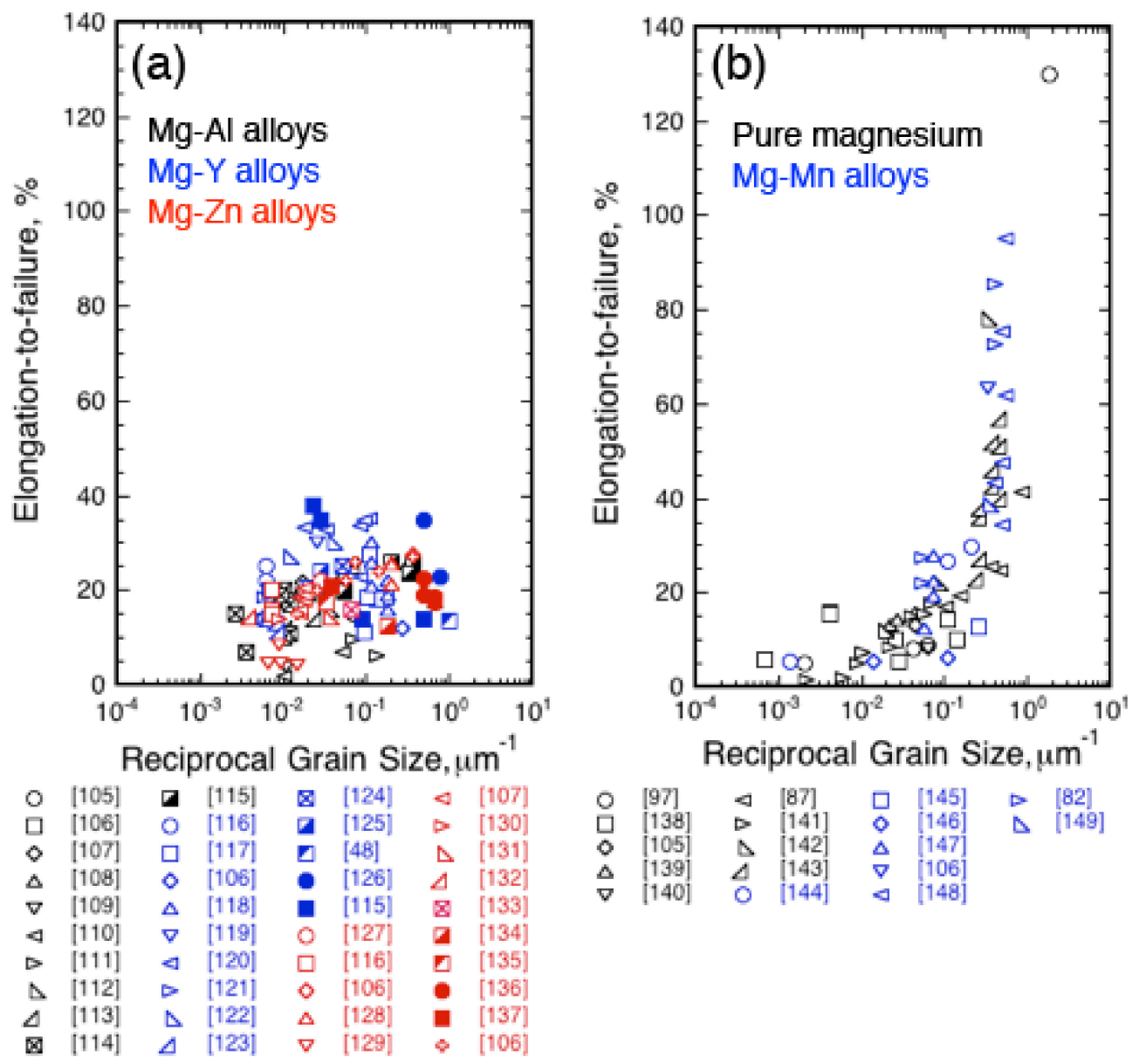

Fig. 5 The variation in elongation-to-failure in tension as a function of reciprocal grain size; (a) magnesium binary alloys containing conventional alloying elements ${ }^{48,71,105-137)}$ and (b) magnesium and Mg-Mn alloy. ${ }^{82,87,97,105,106,138-149)}$ 
influenced by the basal plane distribution, owing to the h.c.p crystal structure. For instance, the elongation-to-failure in tension of an equal-channel-angular extruded alloy is double that obtained from conventional wrought processed magnesium alloys; ${ }^{67)}$ however, Fig. 5 shows that the property of ductility is almost directly proportional to the reciprocal grain size. Notably, in this figure, the tolerance is assumed to result from the chemical composition and wrought processing method. In pure magnesium, more than $100 \%$ elongation-tofailure in tension is exhibited with a refinement to approximately $1 \mu \mathrm{m}$ in grained structures. The relation of elongation-to-failure in tension vs. grain size also obviously depends on the alloying element. The tendency of the $\mathrm{Mg}-$ $\mathrm{Mn}$ alloy is similar to that of pure magnesium. On the contrary, while the aluminum and zinc elements are recognized as common alloying elements to magnesium, the impact/degree of grain refinement on the enhancement of ductility in these binary alloys, such as $\mathrm{Mg}-\mathrm{Al}$ and $\mathrm{Mg}-\mathrm{Zn}$ alloys, is unlikely to be superior to that of pure magnesium. It is well reported that the alloying of RE elements plays a role in reducing the difference in the critical resolved shear stress between the basal and non-basal planes, ${ }^{23,68-71)}$ nevertheless, these binary alloys also have a minor advantage with regard to grain refinement. Although the strategy in most of studies is to control the dislocation slip, these results are interesting in terms of arguing that only controlling this plastic deformation (dislocation slip) is not useful to increase the property of ductility in magnesium and its alloys.

Next, we introduce the experimental results for the plastic deformation behavior of magnesium in the vicinity of the grain boundary and within the matrix (grain interior). Figure 6(a) shows the indentation depth vs. holding time curves obtained from the nano-indentation creep testing. ${ }^{72)}$ This method allows the evaluation and understanding of the localized deformation behavior at small scale. From Fig. 6(a), the indentation response changes with the measurement position. The indentation depth in the vicinity of grain boundary becomes deeper with the indentation holding time at the measurement around the grain boundaries. However, the indentation depth is shallow, when the measurement position is several microns away from grain boundary. This depth vs. time feature is similar to that measured in the grains, which suggests that the deformation mechanism during indentation clearly varies even with the distance from grain boundaries, i.e., $\sim 5 \mu \mathrm{m}$. It is interesting that the distance from grain boundaries influencing the effect on grain boundary compatibility is also reported to be $5 \mu \mathrm{m} .^{29)}$ The strain rate sensitivity ( $m$-value) through the nano-indentation creep testing is calculated to be $\sim 0.5$ and $\sim 0.1$ in the vicinity of the grain boundary and within the matrix, respectively. The $m$-value measured around the vicinity of grain boundaries indicates that grain boundary sliding mainly contributes to deformation. A trace of partial grain boundary sliding is observed even in room-temperature tensile tests using polycrystalline magnesium alloys, ${ }^{30}$ which is in good agreement with the results obtained by nano-indentation creep testing. On the other hand, the $m$-value obtaining from the grain interior provides that the dominant deformation mechanism during indentation creep is assumed to be dislocation slip and/or deformation twining rather than grain boundary sliding. The results through room-temperature creep tests using coarse-grained magnesium, which is not influenced by grain boundary plasticity, indicate that the ratecontrolling mechanism is the basal dislocation slip. ${ }^{73,74)}$

In order to verify the effect of the alloying element on the localized indentation creep behavior in the vicinity of grain boundaries, the variation of indentation depth as a function of the holding time is shown in Fig. 6(b) for the $\mathrm{Mg}-0.3$ at $\% \mathrm{Al}$ alloy. ${ }^{75)}$ The measurement position of this alloy is set to be the same as that of magnesium so as to ignore the crystal orientation and misorientation angle dependency. The indentation behavior of the $\mathrm{Mg}-\mathrm{Al}$ alloy is different from that of magnesium. The alloy exhibits a smaller indentation depth of $\Delta h$ and a higher indentation load value in the vicinity of the grain boundary, compared with those of magnesium. Additionally, this indentation displacement of the alloy is similar to the value obtained from the grain interior when using magnesium. Thus, there is a high probability that the rate-controlling mechanism in the vicinity of grain boundaries in the $\mathrm{Mg}-\mathrm{Al}$ alloy is dislocation slip, which is the same as that of the grain interior of magnesium, as shown in Fig. 6(a). These results suggest that the dominant deformation mechanism for polycrystalline magnesium and its alloys has a close relation to that of the alloying element and the volume fraction in grain boundaries, in other words, grain size. Understanding and controlling the role of these influential factors are very important for attaining good property of ductility.
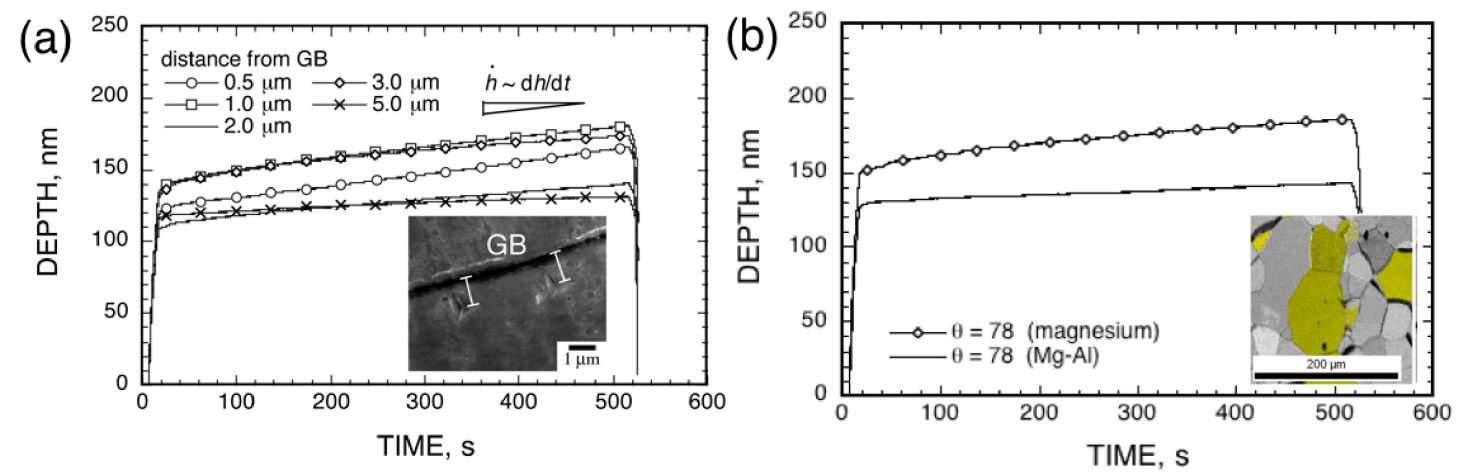

Fig. 6 The indentation depth vs. time obtaining from nanoindentation creep tests (a) in the magnesium and (b) effect of alloying elements on nanoindentation creep behavior. Inset in each image at right-side bottom indicate measurement position. This figure is reconstructed in part from Refs. 72, 75) with permission from Taylor \& Francis and Elsevier, respectively. 

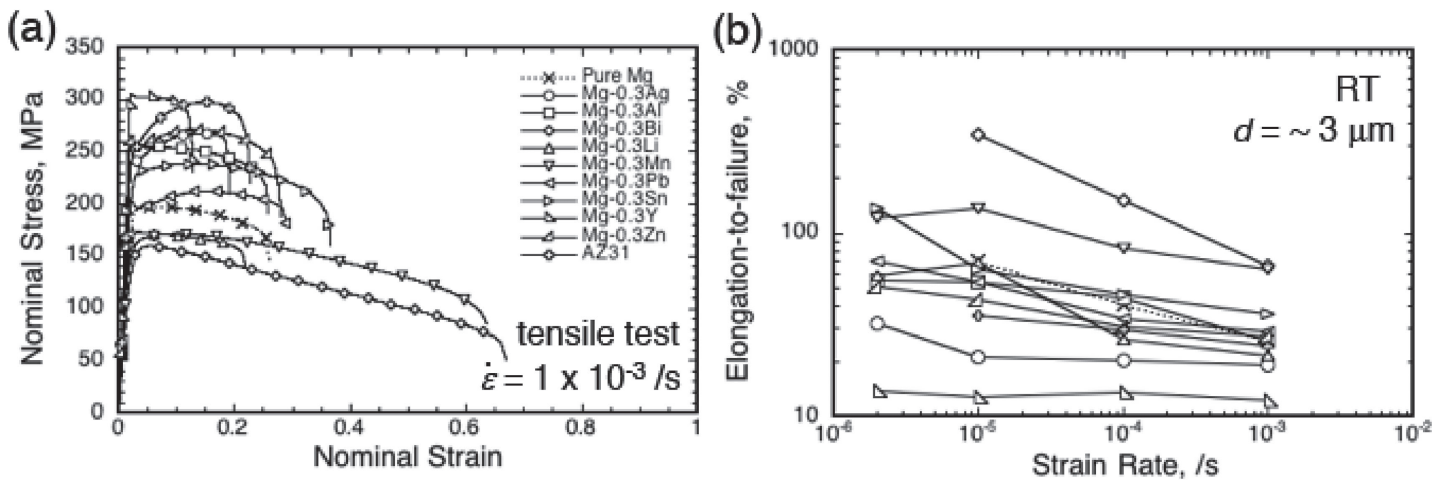

Fig. 7 Room-temperature tensile behavior in fine-grained magnesium and its binary alloys; (a) nominal stress vs. nominal strain curves at quasi-static strain rate $\left(1 \times 10^{-3} / \mathrm{s}\right)$ and $(\mathrm{b})$ variation in elongation-to-failure in tension as a function of strain rate. This figure also includes the results of fine-grained AZ31 alloy.

\subsection{Impact of alloying element on elongation-to-failure in tension}

Based on the content of the previous section, we now introduce the effect of the alloying element on roomtemperature ductility obtaining from fine-grained magnesium binary alloys with a high density of grain boundaries. Figure 7 shows (a) the nominal stress vs. nominal strain curves via tensile testing in the quasi-static strain rate regimes and (b) the relationship between the elongation-to-failure in tension and the initial strain rate. This figure includes the results of an extruded conventional magnesium alloy (AZ31 alloy) having similar microstructures for the purpose of comparing them with those of the binary alloys. ${ }^{76}$ ) The chemical composition of the major alloying element in these cited binary alloys is 0.3 at $\%$. Moreover, since these alloys have an average grain size of approximately $3 \mu \mathrm{m}$ and a basal texture, ${ }^{77}$ the type of alloying element mainly reflects the difference in terms of deformation behavior and mechanical properties. Figure 7(a) shows that the alloying element affects the elongation-to-failure in tension, and the majority of binary alloys show lower ductility than that of magnesium. This trend of ductility is consistent with the results obtained from a conventional magnesium alloy, as shown in Fig. 3(a). In contrast, the elongation-to-failure of the $\mathrm{Mg}-\mathrm{Mn}$ alloy is twice as large as that of magnesium and four times that of the AZ31 alloy. The alloying of the manganese element is found to be outstanding to improve ductility. The elongation-tofailure in tension of the $\mathrm{Mg}-\mathrm{Mn}$ alloy dramatically increases as the tensile strain rate decreases. For example, the elongation-to-failure is over $200 \%$ in a strain rate of $10^{-5} / \mathrm{s}$ even at room-temperature. However, as for the other binary alloys, the tendency for ductility vs. strain rate is similar to those of conventional magnesium alloys. With a decrease of $1 / 1000$ in the strain rate, the improvement for ductility is several \%, which is very low magnitude. Additionally, with regard to the plastic deformation, Fig. 7(a) reveals that the flow stress of a binary alloy adding a specific alloying element (manganese or lithium), which is effective in enhancing ductility, is lower than that of magnesium. In general, the flow stress of alloys is higher than that of pure metals, due to the interaction between the solute elements and the dislocation slips, recognized as the solid solution strengthening mechanism. Nevertheless, the flow stress of the $\mathrm{Mg}-\mathrm{Mn}$ and $\mathrm{Mg}-\mathrm{Li}$ alloys that exhibit good elongation-to- failure in tension is not consistent with this common strengthening mechanism. It is obvious that the reason for the lower flow stress of these alloys is not related to the well known solid solution mechanism. A detailed explanation focusing on the rate-controlling deformation mechanism will be provided in the next section.

\subsection{Deformation mechanism}

Figure 8 shows the Hall-Petch relation for magnesium and its binary alloys, which exhibit unique property of ductility. ${ }^{87)}$ Since the elongation-to-failure in tension is influenced by the strain rate, this figure is divided into two different strain rate regimes of (a) quasi-static strain rate regime $\left(\geq 10^{-4} / \mathrm{s}\right)$ and (b) low strain rate regime $\left(<10^{-4} / \mathrm{s}\right)$. The flow stress obeys the conventional Hall-Petch relation in the quasi-static strain rate regimes (Fig. 8(a)); on the other hand, an inverse HallPetch relation is observed in materials with a size of several microns (Fig. 8(b)). This uncommon behavior generally occurs in ultrafine-grained nickel and copper, owing to the non-site for the Frank-Read source within the matrix. ${ }^{77-80)}$ In magnesium, because the inverse Hall-Petch relation can be observed even in grains having several microns in size, which is a size that is at least 100 times coarser, the major mechanism in magnesium is unlikely to be the same as that of such metallic materials (ultrafine-grained nickel and copper). Figures 9(a) and (b) are typical scanning electron microscopy (SEM) images of the surfaces after room-temperature tensile testing under low strain rate conditions. ${ }^{65)}$ The surface of the $\mathrm{Mg}-\mathrm{Zn}$ alloy, whose elongation-to-failure in tension is similar to that of conventional magnesium alloys, does not exhibit an undulation surface feature. In contrast, the $\mathrm{Mg}-\mathrm{Mn}$ alloy with a quite large ductility clearly indicates a trace of grain boundary sliding, marked by the white arrows. In Figs. 9(c) and (d), the line drawn using the focused ion beam (FIB) technique is aligned before the tensile testing, but the misfit width at the grain boundaries is observed to increase as the deformation progresses. ${ }^{81)}$ Furthermore, it is pointed out that these alloys show different fracture features and origins of fracture. The fracture surface of conventional alloys and binary alloys containing common elements, e.g., aluminum or zinc, show ductile and dimple fractures. Nevertheless, the cavitation behavior, which is well formed at the grain boundary triple junction during superplastic flow, is observed in the $\mathrm{Mg}-\mathrm{Mn}$ alloy. ${ }^{82)}$ It is difficult to say such features are 

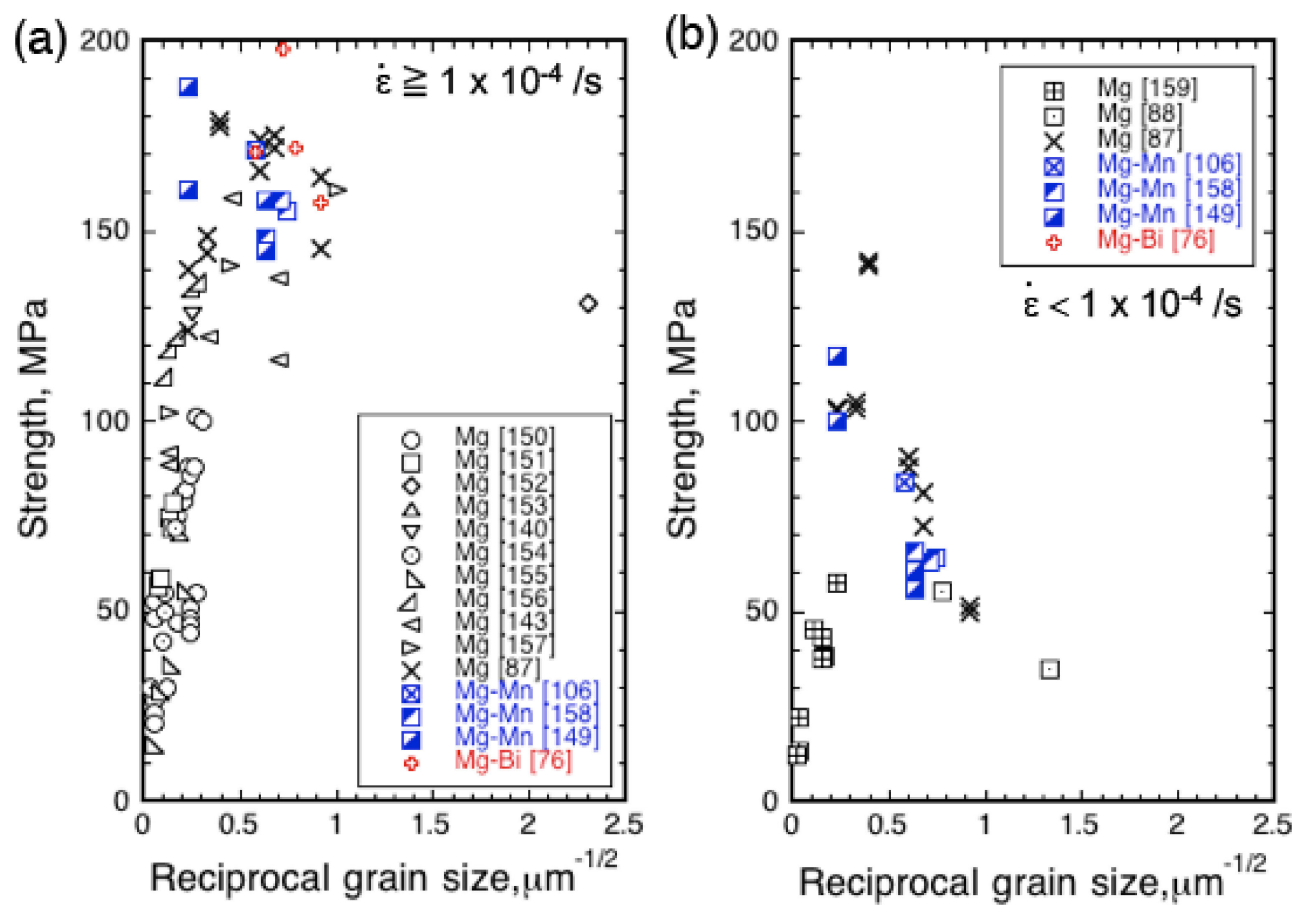

Fig. 8 Hall-Petch relation in magnesium and its binary alloys (a) at quasi-static strain rate regimes (faster than $1 \times$ $\left.10^{-4} / \mathrm{s}\right)^{76,87,106,140,143,149-158)}$ and (b) at low strain rate regimes (lower than $\left.1 \times 10^{-4} / \mathrm{s}\right)^{76,87,88,106,149,158,159)}$ This figure is reproduced in part of Ref. 87) with permission from Springer nature.
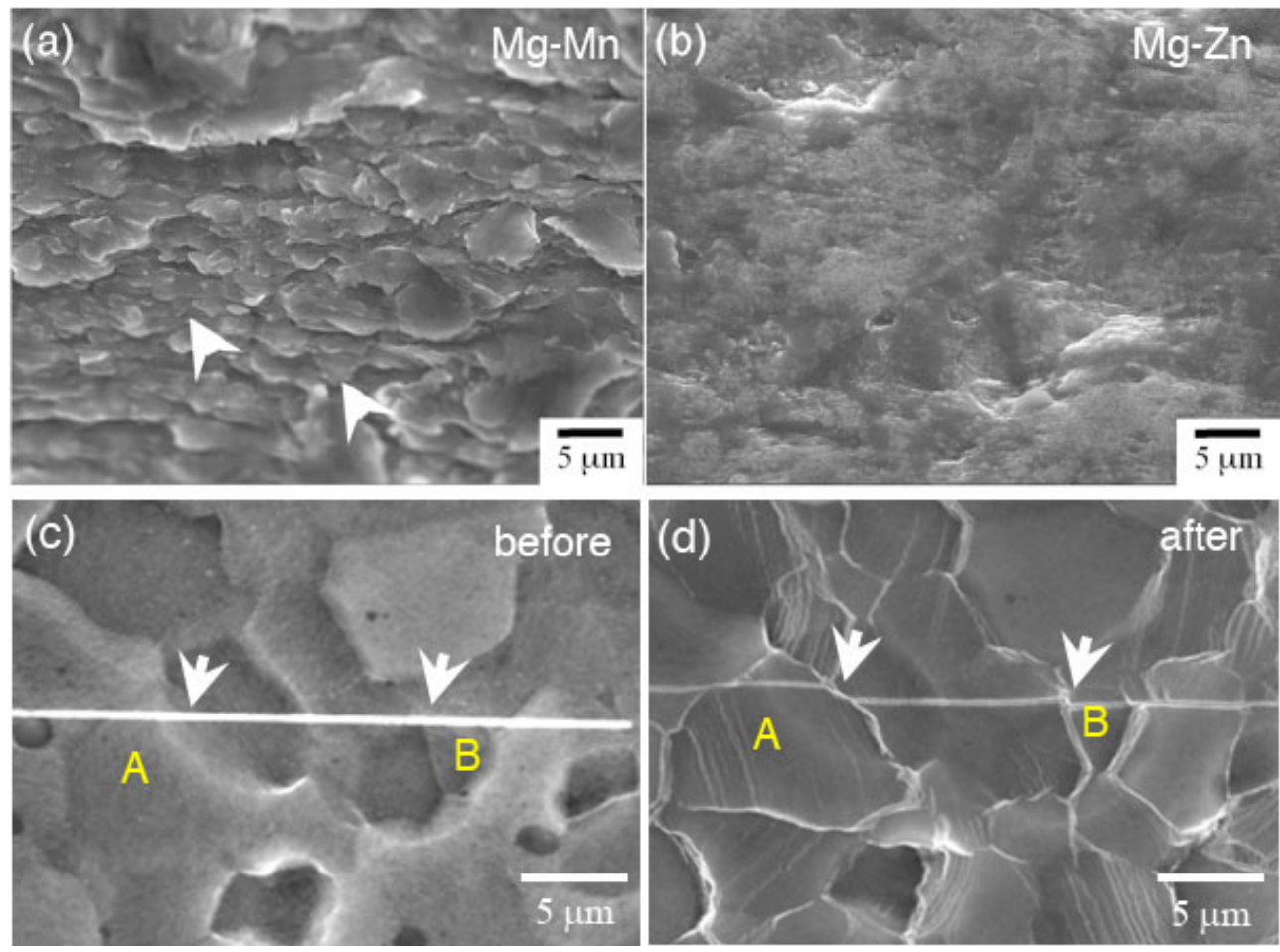

Fig. 9 Typical examples for SEM observation; after room-temperature tensile tested samples at low strain rate regimes in fine-grained (a) $\mathrm{Mg}-\mathrm{Mn}$ and (b) $\mathrm{Mg}-\mathrm{Zn}$ alloys, and difference in surface features (c) before and (d) after tensile testing in fine-grained $\mathrm{Mg}-\mathrm{Mn}$ alloy. White arrows in (a) show the trace of grain boundary sliding. In (c) and (d), white arrows and yellow characteristics correspond to the observed points/regions before and after tensile testing. Figures (a) and (b) are reused in part from Ref. 106) with permission from Taylor \& Francis.

caused by dislocation slips. The above mentioned results suggest that the inverse Hall-Petch relation of magnesium and its alloys is associated with the partial occurrence of grain boundary sliding.
We have not yet determined the definite cause for roomtemperature grain boundary sliding; however, the reason for showing this unique behavior is considered based on concepts of microstructure. The microstructural observations 
of wrought processed magnesium binary alloys indicate grain boundary segregation of the alloying element, as described in an earlier section and reported in several papers. ${ }^{42-48)}$ It is assumed that the key point regarding a remarkably large ductility is whether or not grain boundary segregation plays a role in enhancing grain boundary sliding. The results obtained from the first-principles calculation method reveal that, when an alloying element such as yttrium for the prevention of grain boundary sliding exists at grain boundaries, the electrons of magnesium and such element creates with strong bonds along the specific direction. On the contrary, in the case of manganese, the electrons of magnesium and manganese tend to have uniform bonds. These symmetry or asymmetry bonding behaviors affect grain boundary plasticity from an atomistic perspective. ${ }^{82)}$ Regarding lithium, the valence electron exists in the $s$-orbits; as a result, this kind of electron is in non-localization status and behaves as a free-electron. ${ }^{83)}$ Nonetheless, it is noted that these arguments are not considered as a comprehensive causes in this case, since the actual bulked materials consist of a huge variety of grain boundaries. It will be necessary to consider this point in detail in the future.

Figure 10 is a schematic illustration of the flow stress vs. strain rate including well-known deformation mechanisms such as grain boundary sliding, dislocation slips and deformation twinning in metallic materials. The gray shaded area indicates the strain rate regimes evaluated by conventional testing methods/facilities. ${ }^{84)}$ The bold line indicates an example of the rate-controlling mechanism. In the case of the binary alloys containing common alloying elements, as shown in Fig. 7(b), the elongation-to-failure is at most several $\%$ and the $m$-value is small even in low strain rate regimes. ${ }^{65,76)}$ In other words, these alloying elements are unlikely to have enhancing effects for room-temperature grain boundary sliding. Since grain boundary sliding is generally difficult to observe in such very low strain rate regimes using conventional methods/facilities, the dislocation slip is the major deformation mechanism, which is similar to that of general plastic deformation. Attention must be paid to the fact that, in the compressive testing state, the

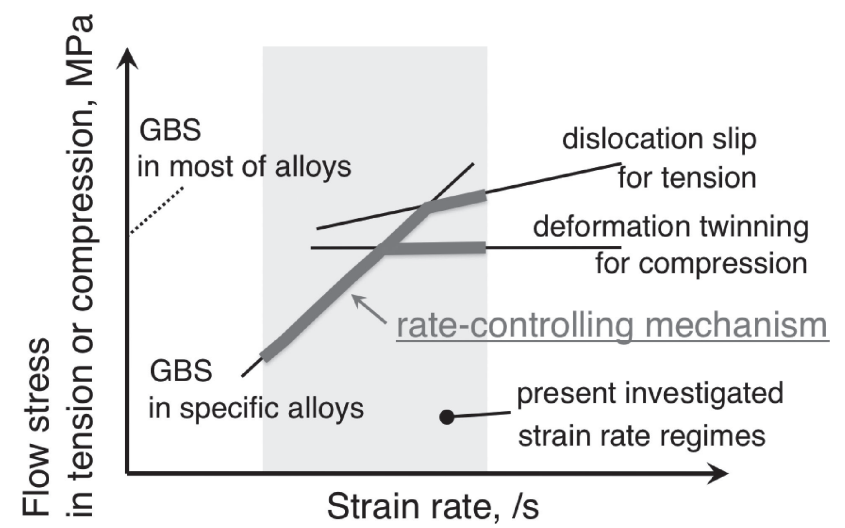

Fig. 10 The simple relation for flow stress in tension or compression vs strain rate in the conventional and specific magnesium alloys at roomtemperature. GBS indicates grain boundary sliding. It is noted that three different deformation mechanisms, i.e., GBS, dislocation slip and twinning, depend on grain sizes and testing temperatures. This figure is reused in part from Ref. 84) with permission from JIM. flow stress corresponds to deformation twinning, due to its relationship with the crystal orientation and stress applied direction. On the other hand, lithium and manganese play a role in enhancing/activating for room-temperature grain boundary sliding. Hence, partial grain boundary sliding is observed in fine-grained $\mathrm{Mg}-\mathrm{Li}$ and $\mathrm{Mg}-\mathrm{Mn}$ alloys with a high density of grain boundaries at low and quasi-static strain rate regimes. However, regardless of these specific alloys, it is noted that the rate-controlling mechanism changes from grain boundary sliding to dislocation slips with increase in the testing speeds.

One of the reasons for the enhancement of grain boundary sliding is associated with grain boundary segregation, as mentioned above. Even in the alloying element, which leads to high grain boundary sliding activity, it is necessary to control the site for grain boundary segregation. The deformation mechanism is influenced by the volume fraction of the grain boundary, which is the segregation site for the solute elements. Although the grain size and chemical composition would be constant, the $\mathrm{Mg}-\mathrm{Mn}$ alloy containing a high density of low-angle grain boundaries with very little free volume shows an elongation-to-failure of around 20$30 \%$. The flow stress and ductility of this alloy do not also have strain rate dependence. These values are quite different from the results, as shown in Figs. 5 and 7. This results from the fact that the major deformation mechanism is reported to be dislocation slips rather than grain boundary sliding. ${ }^{85)}$

Finally, we consider the reason for room-temperature grain boundary sliding based on the accommodated mechanism. Grain boundary sliding is a deformation mechanism that is widely recognized as superplastic behavior showing large ductility such as starch syrup. ${ }^{86)}$ In order to retain the plastic deformation through grain boundary sliding, an accommodation mechanism is necessary for operation. The constitutive equation in metallic materials during creep behavior is generally expressed by the following equation: ${ }^{86)}$

$$
\dot{\varepsilon}=A\left(\frac{G b}{k T}\right)\left(\frac{\sigma}{G}\right)^{n}\left(\frac{b}{d}\right)^{p} D
$$

where $\dot{\varepsilon}$ is strain rate, $\sigma$ is flow stress, $G$ is shear modulus, $n$ is stress exponent (= reciprocal in strain rate sensitivity), $k$ is Boltzman constant, $b$ is Burgurs vector, $d$ is grain size, $p$ is grain size exponent and $D$ is diffusion coefficient. Table 1 is listed in recent studies and reports as for the roomtemperature creep behavior of magnesium and its alloys. $^{73,76,87-95)}$ When dislocation slip is the rate-controlling mechanism (e.g., $m<0.1$ ), the $m$-value or activation volume, which has a close relation to the deformation mechanism, indicates small or large in values, respectively. Compared with the values of conventional magnesium alloys, magnesium and its alloys listed in Table 1 have higher $m$-values or lower activation volumes. In particular, the $m$-value increases (= activation volume decreases) with grain refinement and/or a reduction in the strain rates. While there exist a few results with regard to activation energy, the alloys having grain sizes of several dozen $\mu \mathrm{m}$ have the activation energy of around $20 \mathrm{~kJ} / \mathrm{mol}^{30}$ ) Such low activation energy suggests that dislocation slips are associated with grain boundary sliding. In addition, for the alloy with a grain size of more than $100 \mu \mathrm{m}$, the activation 
Table 1 Results of room-temperature creep testing in various magnesium and its alloys. ${ }^{73,76,87-95)}$

\begin{tabular}{lclllr}
\hline material & grain size, $\mu \mathrm{m}$ method & $\mathrm{n}(=1 / \mathrm{m})$ or $\mathrm{V}$ & $\mathrm{Q}, \mathrm{kJ} / \mathrm{mol}$ & Ref \\
\hline Pure $\mathrm{Mg}$ & 1.2 & tensile & $\mathrm{V}=8 \mathrm{~b}^{3}\left(10^{-6}-10^{-4} / \mathrm{s}\right)$ & $84(\mathrm{RT}-323 \mathrm{~K})$ & {$[87]$} \\
Pure $\mathrm{Mg}$ & $\sim 0.5-2$ & tensile & $\mathrm{m}=0.2\left(10^{-5}-10^{-1} / \mathrm{s}\right)$ & $75(\mathrm{RT}-373 \mathrm{~K})$ & {$[88]$} \\
Pure $\mathrm{Mg}$ & 2 & tensile & $\mathrm{n}=4\left(10^{-5}-10^{-3} / \mathrm{s}\right)$ & -- & {$[89]$} \\
Pure $\mathrm{Mg}$ & $>100$ & tensile & $\mathrm{n}=3.1\left(10^{-9}-10^{-8} / \mathrm{s}\right)$ & $12(200 \mathrm{~K}-\mathrm{RT})$ & {$[73]$} \\
Pure $\mathrm{Mg}$ & 0.045 & compression & $\mathrm{n}=5\left(10^{-4}-10^{-3} / \mathrm{s}\right)$ & -- & {$[90]$} \\
Pure $\mathrm{Mg}$ & 0.06 & compression & $\mathrm{V}=12 \mathrm{~b}^{3}\left(10^{-5}-10^{-2} / \mathrm{s}\right)$ & -- & {$[91]$} \\
Pure $\mathrm{Mg}$ & $\sim 2-3$ & nanoindentation & $\mathrm{V}=25 \mathrm{~b}^{3}\left(10^{-3}-10^{0} / \mathrm{s}\right)$ & -- & {$[92]$} \\
Pure $\mathrm{Mg}$ & $>100$ & nanoindentation & $\mathrm{V}=45 \mathrm{~b}^{3}\left(10^{-3}-10^{0} / \mathrm{s}\right)$ & -- & {$[93]$} \\
Pure $\mathrm{Mg}$ & 80 & nanoindentation & $\mathrm{V}=28 \mathrm{~b}^{3}\left(10^{-5}-10^{-2} / \mathrm{s}\right)$ & $0.69-1.01^{*}(\mathrm{RT}-573 \mathrm{~K})[94]$ \\
$\mathrm{Mg}-5 \mathrm{Al}$ & 0.045 & tensile & $\mathrm{n}=1.5\left(10^{-7}-10^{-5} / \mathrm{s}\right)$ & $76(\mathrm{RT}-323 \mathrm{~K})$ & {$[95]$} \\
$\mathrm{Mg}-0.3 \mathrm{Bi}$ & 3 & tensile & $\mathrm{m}=0.2-0.3\left(10^{-5}-10^{-4} / \mathrm{s}\right)$ & $85(300-323 \mathrm{~K})$ & {$[76]$} \\
$\mathrm{Mg}-0.3 \mathrm{Mn}$ & 2.8 & tensile & $\mathrm{m}=0.2\left(10^{-5}-10^{-4} / \mathrm{s}\right)$ & $74(300-323 \mathrm{~K})$ & {$[76]$} \\
\hline
\end{tabular}

$b:$ Burgers vector $\left(=3.21 \times 10^{-10} \mathrm{~m}\right.$ in magnesium $\left.[160]\right),{ }^{*}:$ unit $=\mathrm{eV}$

energy is of several values in $\mathrm{kJ} / \mathrm{mol}$. Under those conditions, the atomic shuffling mechanism operates in the vicinity of grain boundaries. ${ }^{73,74,96)}$ On the other hand, the fine-grained alloy has the activation energy of $90 \mathrm{~kJ} / \mathrm{mol}$, which is close to grain boundary diffusion. ${ }^{76,86,87)}$ This mechanism of the fine-grained alloy is not consistent with previously discussed studies using coarse- and meso-grained alloys; however, it is interesting to observe that the deformation behavior is the same as that of nano-indentation creep testing, as shown in Fig. 6(a). Note that the other model, such as grain boundary rotational model, has been also proposed. ${ }^{97)}$ In the future, it is necessary to revisit this in more detail.

Normalized plots using the shear modulus and several material parameters are presented in Fig. 11. These plotted

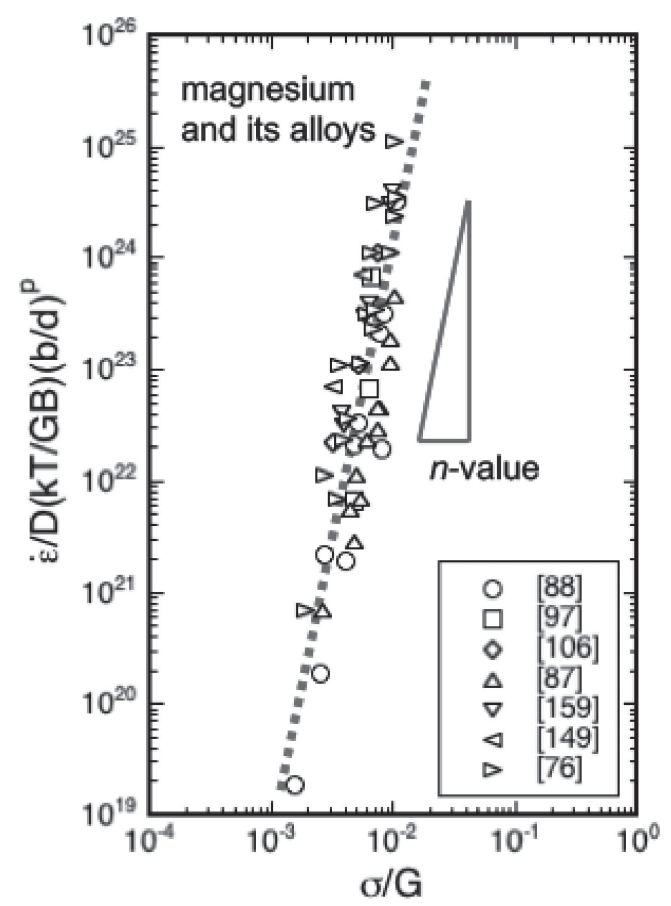

Fig. 11 The variation in $\dot{\varepsilon} / \mathrm{D}(\mathrm{kT} / \mathrm{Gb})(\mathrm{b} / \mathrm{d})^{\mathrm{p}}$ as a function of $(\sigma / \mathrm{G})$ in finegrained magnesium and its alloys. ${ }^{76,87,88,97,106,149,159)}$ data are cited from the tensile tested results of the finegrained magnesium and its alloys (grain size of less than $5 \mu \mathrm{m}$ ) in strain rates of lower than $10^{-3} / \mathrm{s}$. Even though the fact that testing conditions and specimens varied, the flow stress vs. strain rates showing superior elongation tends to follow a similar pattern. As mentioned previously, there are many kinds of accommodation mechanism; nevertheless, because the normalized plots do not show large differences, it is assumed that the rate-controlling mechanism has the same behavior.

\section{Conclusion Remarks}

This review focused on solid solution elements that are able to solute into magnesium. Recent studies regarding good properties of ductility due to grain boundary sliding have indicated that the alloying of bismuth element has the same or even a superior role as compared to that of manganese element. ${ }^{76,98)}$ The $\mathrm{Mg}-\mathrm{Bi}$ alloy produced by conventional extrusion exhibits an elongation-to-failure in tension of more than $150 \%$ even at an initial tensile strain rate of $1 \times 10^{-3} / \mathrm{s}$. This large ductility is very similar to superplastic behavior. ${ }^{76)}$ However, the solubility of bismuth into magnesium is low in the temperature ranges of wrought processing. Thus, grain boundary segregation is unlikely to occur and to observe in this extruded $\mathrm{Mg}-\mathrm{Bi}$ alloy. This point is not the same as those in the extruded $\mathrm{Mg}-\mathrm{Mn}$ alloy. It is interesting to note from an academic viewpoint that the microscopic structural factors that enhance grain boundary sliding are different between the $\mathrm{Mg}-\mathrm{Bi}$ and $\mathrm{Mg}-\mathrm{Mn}$ alloys. In contrast, since silicon does not have the characteristic of solubility in magnesium, as shown in Fig. 1, it readily forms an intermetallic consisting of the $\mathrm{Mg}_{2} \mathrm{Si}$ phase. These intermetallics are used to control microstructures, i.e., prevention for grain growth, at high temperature ranges. For instance, the microstructures of the $\mathrm{Mg}-\mathrm{Si}$ alloy having ultrafine-grains do not dramatically change even at a temperature of $773 \mathrm{~K}$. Consequently, this alloy exhibits an elongation-to-failure of more than $250 \%$ at this elevated temperature in a strain rate of $1 / \mathrm{s}$, which corresponds to the high-strain rate superplasticity. ${ }^{99}$ ) 
It is widely accepted that the crystal structure of magnesium transitions from h.c.p to body centered cubic (b.c.c) via the specific alloying element of lithium with a high chemical composition. This element is also known to cause both weight reduction and easy/good secondary formability. Furthermore, the density of the $\mathrm{Mg}-\mathrm{Li}$ alloy containing over $33 \%$ in lithium is less than 1; as a result, this alloy can float on water. ${ }^{100)}$ Regarding the enhancement for room-temperature ductility, the ultrafine-grained $\mathrm{Mg}-\mathrm{Li}$ alloy with two phases consisting of h.c.p and b.c.c crystal structures is reported to show the elongation-to-failure in tension of 300\% at quasi-static strain rate regimes. ${ }^{101)}$ The characteristics of scandium are similar to those of lithium. The alloying of this element results in the transformation of the crystal structure from h.c.p to b.c.c. The phase transformation can be induced by adding at least $20 \%$ scandium. ${ }^{102)}$ In addition, scandium belongs to the RE element group; hence, its atomic radius is very different from that of magnesium, and this difference highly contributes to the strengthening effect. ${ }^{103)}$

Recent numerical studies have pointed out that the electronic behavior of titanium among magnesium tends to appear as unique and interesting. This solute element plays a role in the non-basal dislocation slip activity and grain boundary strengthening (= high toughness) ${ }^{104)}$ The preparation of a solid solution $\mathrm{Mg}$-Ti binary alloy is not possible with the present material processing technology; however, future technological advances may allow the production of this kind of new materials. In fact, the formulation of new materials/alloys based on the use of artificial intelligence and materials genomes may be very close to becoming real and practical. We believe and except that this review will be useful in the design of novel magnesium alloys.

\section{Acknowledgements}

The author is grateful thanks to Prof. H. Yoshinaga (Kyushu University) and Dr. T. Tsuru (Japan Atomic Energy Agency) for their constructive comments and suggestions, and to Dr. Y. Osawa (National Institute for Materials Science), Ms. R. Komatsu and Ms. Y. Kobayashi for their kind helps. The preparation for this review paper is partially supported by the JSPS Grant-in-Aid (C) for Scientific Research in No. 16K06783 and Scientific Research on Innovative Areas "MFS Materials Science in No. 18H05477" and "Bulk Nanocrystructured Metals in No. 25102712”.

\section{REFERENCES}

1) H. Yoshinaga and R. Horiuchi: Trans. JIM 3 (1962) 220-226.

2) H. Yoshinaga and R. Horiuchi: Trans. JIM 4 (1963) 1-8.

3) H. Yoshinaga and R. Horiuchi: Trans. JIM 4 (1963) 134-141.

4) H. Yoshinaga and R. Horiuchi: Trans. JIM 5 (1964) 14-21.

5) R.E. Reed-Hill and W.D. Robertson: Acta Metall. 5 (1957) 717-727.

6) R.E. Reed-Hill and W.D. Robertson: Acta Metall. 5 (1957) 728-737.

7) A. Akhtar and E. Teghtsoonian: Acta Metall. 17 (1969) 1339-1349.

8) A. Akhtar and E. Teghtsoonian: Acta Metall. 17 (1969) 1351-1356.

9) W.F. Sheely and R.R. Nash: Trans. Metall. AIME 218 (1960) 416423.

10) P. Ward Flynn, J. Mote and J.E. Dorn: Trans. Metall. AIME 221 (1961) 1148-1154.
11) B.C. Wonsiewicz and W.A. Backofen: Trans. Metall. AIME 221 (1967) 1422-1431.

12) K. Halada and K. Ijima: Materia Japan 43 (2004) 264-269.

13) Metals Data Book, The Japan Institute of Metals and Materials, (Maruzen, Tokyo, Japan, 2004).

14) T.B. Massalski: Binary Alloy Phase Diagrams, 2nd ed., (ASM International, Materials Park, OH, 1990).

15) L.L. Rokhlin: Magnesium Alloys Containing Rare Earth Metals, (Taylor \& Francis, 2003).

16) M. Suzuki, H. Sato, K. Maruyama and K. Oikawa: Mater. Sci. Eng. A 252 (1998) 248-255.

17) Y. Kawamura, K. Hayashi, A. Inoue and T. Masumoto: Mater. Trans. 42 (2001) 1172-1176.

18) E. Abe, Y. Kawamura, K. Hayashi and A. Inoue: Acta Mater. 50 (2002) 3845-3857.

19) J.A. Yasi, L.G. Hector and D.R. Trinkle: Acta Mater. 58 (2010) 5704 5713.

20) T. Nogaret, W.A. Curtin, J.A. Yasi, L.G. Hector and D.R. Trinkle: Acta Mater. 58 (2010) 4332-4343.

21) S. Ganeshan, S.L. Shang, Y. Wang and Z.K. Liu: Acta Mater. 57 (2009) 3876-3884.

22) T. Tsuru and D.C. Chrzan: Sci. Rep. 5 (2015) 8793.

23) T. Tsuru, Y. Udagawa, M. Yamaguchi, M. Itakura, H. Kaburaki and Y. Kaji: J. Phys. Condens. Matter 25 (2013) 022202.

24) H. Somekawa: Materia Japan 47 (2008) 157-160.

25) D. Ando, J. Koike and Y. Sutou: Acta Mater. 58 (2010) 4316-4324.

26) D. Ando, J. Koike and Y. Sutou: Mater. Sci. Eng. A 600 (2014) 145152.

27) H. Somekawa, A. Singh and T. Mukai: Philos. Mag. Lett. 89 (2009) $2-10$.

28) V. Kaushik, R. Narasimhan and R.K. Mishra: Mater. Sci. Eng. A 590 (2014) 174-185.

29) J. Koike, T. Kobayashi, T. Mukai, H. Watanabe, M. Suzuki, K. Maruyama and K. Higashi: Acta Mater. 51 (2003) 2055-2065.

30) J. Koike, R. Ohyama, T. Kobayashi, M. Suzuki and K. Maruyama: Mater. Trans. 44 (2003) 445-451.

31) I.J. Beyerlein, L. Capolungo, P.E. Marshall, R.J. McCabe and C.N. Tome: Philos. Mag. 90 (2010) 2161-2190.

32) J. Wang, I.J. Beyerlein and C.N. Tome: Scr. Mater. 63 (2010) 741746.

33) M.R. Barnett: Scr. Mater. 59 (2008) 696-698.

34) J.W. Christian and S. Mahajan: Prog. Mater. Sci. 39 (1995) 1-157.

35) D. Hull: Acta Metall. 9 (1961) 191-204.

36) M.J. Marcinkowski and H.A. Lipsitt: Acta Metall. 10 (1962) 95-111.

37) H. Somekawa, K. Nakajima, A. Singh and T. Mukai: Philos. Mag. Lett. 90 (2010) 831-839.

38) H. Somekawa, T. Inoue and K. Tsuzaki: Philos. Mag. 93 (2013) 45824592.

39) D.A. Basha, H. Somekawa and A. Singh: Scr. Mater. 142 (2018) 5054.

40) M.C. Inman and H.R. Tipler: Acta Metall. 6 (1958) 73-84.

41) R.A. Mulford, C.J. McMahon, D.P. Pope and H.C. Feng: Metall. Trans. A 7 (1976) 1183-1195.

42) H. Watanabe, A. Owashi, T. Uesugi, Y. Takigawa and K. Higashi: Philos. Mag. 92 (2012) 787-803.

43) J.P. Hadorn, K. Hantzschen, S. Yi, J. Bohlen, D. Letzing, J.A. Wollmershauser and S.R. Agnew: Metall. Mater. Trans. A 43 (2012) 1347-1362.

44) N. Stanford, G. Sha, J.H. Xia, S.P. Ringer and M.R. Barnett: Scr. Mater. 65 (2011) 919-921.

45) Y. Huang, H. Dieringa and K.U. Kainer: Fat Frac. Eng. 36 (2013) 308-315.

46) M. Bugnet, A. Kula, M. Niewezas and G.A. Botton: Acta Mater. 79 (2014) 66-73.

47) J.D. Robson, S.J. Haigh, B. Davis and D. Griffiths: Metall. Mater. Trans. A 47 (2016) 522-530.

48) D. Zhang, H. Wen, M.A. Kumar, F. Chen, L. Zhang, I.J. Beyerlein, J.M. Schoenung, S. Mahajan and E.J. Laernia: Acta Mater. 120 (2016) 75-85.

49) M.P. Seah: J. Phys. F 10 (1980) 1043-1064.

50) D. McLean: Grain Boundaries in Metals, (Oxford Press, London, 
1957).

51) H.W. King: J. Mater. Sci. 1 (1966) 79-90.

52) R.S. Busk: JOM 2 (1950) 1460-1464.

53) S. Miura, S. Imagawa, T. Toyoda, K. Ohkubo and T. Mohri: Mater. Trans. 49 (2008) 952-956.

54) T. Hase, T. Ohtagaki, M. Yamaguchi, N. Ikeo and T. Mukai: Acta Mater. 104 (2016) 283-294

55) H. Somekawa, A. Singh and T. Inoue: Mater. Sci. Eng. A 612 (2014) 172-178.

56) J.F. Nie, Y.M. Zhu, J.Z. Liu and X.Y. Fang: Science 340 (2013) $957-$ 960.

57) Y. Xin, Y. Zhang, H. Yu, H. Chen and Q. Liu: Mater. Sci. Eng. A 644 (2015) 365-373.

58) D. Sarker, J. Friedman and D.L. Chen: J. Alloy. Compd. 611 (2014) 341-350.

59) D. Drozdenko, P. Dobron, S. Yi, K. Horvath, D. Letzing and J. Bohlen: Mater. Charact. 139 (2018) 81-88.

$60)$ C.D. Barrett, A. Imandoust and H. El Kadiri: Scr. Mater. 146 (2018) 46-50.

61) Y. Cui, Y. Li, S. Sun, H. Bian, H. Hung, Z. Wang, Y. Koizumi and A. Chiba: Scr. Mater. 101 (2015) 8-11.

62) Y.J. Cui, Y.P. Li, Z.C. Wang, Q. Lei, Y. Koizumi and A. Chiba: Int. J. Plast. 99 (2017) 1-18.

63) H. Somekawa, H. Watanabe, D.A. Basha, A. Singh and T. Inoue: Scr. Mater. 129 (2017) 35-38.

64) H. Somekawa and T. Tsuru: Scr. Mater. 130 (2017) 114-118.

65) H. Somekawa, A. Singh, T. Inoue and K. Tsuzaki: Philos. Mag. 94 (2014) 3317-3330

66) T. Tsuru, H. Somekawa and D.C. Chrzan: Acta Mater. 151 (2018) 7886.

67) T. Mukai, M. Yamanoi, H. Watanabe and K. Higashi: Scr. Mater. 45 (2001) 89-94.

68) S. Sandlöbes, Z. Pei, M. Friák, L.F. Zhu, F. Wang, S. Zaefferer, D. Raabe and J. Neugebauer: Acta Mater. 70 (2014) 92-104.

69) H. Somekawa, M. Yamaguchi, Y. Osawa, A. Singh, M. Itakura, T. Tsuru and T. Mukai: Philos. Mag. 95 (2015) 869-885.

70) K.H. Kim, J.B. Jeon, N.J. Kim and B.J. Lee: Scr. Mater. 108 (2015) 104-108.

71) S.R. Agnew, M.H. Yoo and C.N. Tome: Acta Mater. 49 (2001) $4277-$ 4289

72) H. Somekawa and T. Mukai: Philos. Mag. Lett. 90 (2010) 883-890.

73) T. Matsunaga, T. Kameyama, K. Takahashi and E. Sato: Mater. Trans. 50 (2009) 2858-2864.

74) T. Matsunaga, T. Kameyama, K. Takahashi and E. Sato: Mater. Trans. 50 (2009) 2865-2872.

75) H. Somekawa and T. Mukai: Mater. Lett. 76 (2012) 32-35.

76) H. Somekawa and A. Singh: Scr. Mater. 150 (2018) 26-30.

77) M.A. Meyers, A. Mishra and D.J. Benson: Prog. Mater. Sci. 51 (2006) $427-556$.

78) J. Schiøtz and K.W. Jacobsen: Science 301 (2003) 1357-1359.

79) J. Schiøtz, F.D. Di Tolla and K.W. Jacobsen: Nature 391 (1998) 561 563.

80) K.S. Kumar, H. Van Swygenhoven and S. Suresh: Acta Mater. 51 (2003) 5743-5774.

81) H. Somekawa, H. Watanabe and T. Mukai: Philos. Mag. 94 (2014) $1345-1360$

82) S. Ogata: private communication.

83) H. Somekawa and T. Tsuru: Mater. Sci. Eng. A 708 (2017) 267-273.

84) H. Somekawa, A. Singh and T. Inoue: Mater. Trans. 58 (2017) 1089 1092

85) H. Somekawa, D.A. Basha and A. Singh: Mater. Sci. Eng. A $\mathbf{7 4 6}$ (2019) 162-166.

86) O.D. Sherby and J. Wadsworth: Prog. Mater. Sci. 33 (1989) 169-221.

87) H. Somekawa and T. Mukai: Metall. Mater. Trans. A 46 (2015) 894 902.

88) R.B. Figueiredo, S. Sabbaghianrad, A. Giwa, J.R. Greer and T.G. Langdon: Acta Mater. 122 (2017) 322-331.

89) C.L. Wang, T. Mukai and T.G. Nieh: J. Mater. Res. 24 (2009) 16151618.

90) S. Hwang, C. Nishimura and P.G. McCormick: Scr. Mater. 44 (2001) $1507-1511$
91) H.J. Choi, Y. Kim, J.H. Shin and D.H. Bae: Mater. Sci. Eng. A 527 (2010) 1565-1570.

92) H. Somekawa and C.A. Schuh: Acta Mater. 59 (2011) 7554-7563.

93) H. Somekawa and C.A. Schuh: Scr. Mater. 68 (2013) 416-419.

94) M. Haghshenas, V. Bhakhri, R. Oviasuyi and R.J. Kiassen: MRS Commun. 5 (2015) 513-518.

95) B.W. Chua, L. Lu and M.O. Lai: Mater. Res. Bull. 41 (2006) 21022110.

96) T. Matsunaga, T. Kameyama, S. Ueda and E. Sato: Philos. Mag. 90 (2010) 4041-4054.

97) C.L.P. Silva, A.C. Oliveira, C.G.F. Costa, R.B. Figueiredo, M.F. Leite, M.M. Pereira, V.F.C. Lins and T.G. Langdon: J. Mater. Sci. 52 (2017) 5992-6003.

98) H. Somekawa, A. Singh, R. Sahara and T. Inoue: Sci. Rep. 8 (2018) 656.

99) M. Mabuchi and K. Higashi: Philos. Mag. A 74 (1996) 887-905.

100) Y. Kojima: Sci. Ind. 48 (1995) 42-44.

101) K. Edalati, T. Masuda, M. Arita, M. Furui, X. Sauvage, Z. Horita and R.Z. Valiev: Sci. Rep. 7 (2017) 2662.

102) Y. Ogawa, D. Ando, Y. Sutou and J. Koike: Science 353 (2016) 368370.

103) D. Ando, Y. Ogawa, T. Suzuki, Y. Sutou and J. Koike: Mater. Lett. 161 (2015) 5-8.

104) T. Tsuru: private communication.

105) A. Kumar, G.K. Meenashisundaram, V. Manakari, G. Parande and M. Gupta: J. Alloy. Compd. 695 (2017) 3612-3620.

106) H. Somekawa, A. Singh, T. Mukai and T. Inoue: Philos. Mag. 96 (2016) 2671-2685.

107) Y. Chino, T. Ueda, Y. Otomatsu, K. Sassa, X. Huang, K. Suzuki and M. Mabuchi: Mater. Trans. 52 (2011) 1477-1482.

108) A.S. El-Amoush: J. Alloy. Compd. 463 (2008) 475-479.

109) S.C. Kurnaz, H. Sevik, S. Acikgoz and A. Ozel: J. Alloy. Compd. 509 (2011) 3190-3196.

110) H. Wang, K. Zhou, G. Xie, X. Liang and Y. Zhao: Mater. Sci. Eng. A 560 (2013) 787-791.

111) S. Seetharaman, C. Blawert, B.M. Ng, W.L.E. Wong, C.S. Goh, N. Hort and M. Gupta: J. Alloy. Compd. 648 (2015) 759-770.

112) N. Stanford, I. Sabirov, G. Sha, A.L. Fontaine, S.P. Ringer and M.R Barnett: Metall. Mater. Trans. A 41 (2010) 734-743.

113) Y. Chino, M. Kado, T. Ueda and M. Mabuchi: Metall. Mater. Trans. A 42 (2011) 1965-1973.

114) H. Cao and M. Wessen: Metall. Mater. Trans. A 35 (2004) 309-319.

115) H. Somekawa: unpublished data.

116) S.A. Farzadfar, E. Martin, M. Sanjari, E. Essadiqi, M.A. Wells and S. Yue: Mater. Sci. Eng. A 534 (2012) 209-219.

117) J. Wei, G. Huang, D. Yin, K. Li, Q. Wang and H. Zhou: Metals 7 (2017) 119

118 J.W. Lu, D.D. Yin, G.H. Huang, G.F. Quan, Y. Zeng, H. Zhou and Q.D. Wang: Mater. Sci. Eng. A 700 (2017) 598-608.

119) B.L. Wu, Y.H. Zhao, X.H. Du, Y.D. Zhang, F. Wagner and C. Esling: Mater. Sci. Eng. A 527 (2010) 4334-4340.

120) G.H. Huang, D.D. Yin, J.W. Lu, H. Zhou, Y. Zeng, G.F. Quan and Q.D. Wang: Mater. Sci. Eng. A 720 (2018) 24-35.

121) A. Kula, X. Jia, R. Mishra and M. Niewczas: Metall. Mater. Trans. B 46 (2016) 3333-3342.

122) B.Q. Shi, R.S. Chen and W. Ke: Mater. Sci. Eng. A 560 (2013) 62-70.

123) L. Gao, R.S. Chen and E.H. Han: J. Alloy. Compd. 472 (2009) 234 240.

124) A. Singh, H. Somekawa and T. Mukai: Mater. Sci. Eng. A 698 (2017) 238-248.

125) S. Sandlöbes, S. Zaefferer, I. Schestakow, S. Yi and R. GonzalezMartinez: Acta Mater. 59 (2011) 429-439.

126) I. Kawarada, R. Zheng, A. Shibata, H. Somekawa, S. Ogata and N. Tsuji: Magnesium Technology 2017, ed. by K. Solanki, D. Orlov, A. Singh and N. Neelameggham, (Springer, Cham, 2017) pp. 283-287.

127) C.D. Li, X.J. Wang, W.Q. Liu, K. Wu, H.L. Shi, C. Ding, X.S. Hu and M.Y. Zheng: Mater. Sci. Eng. A 597 (2014) 264-269.

128) H. Somekawa, Y. Osawa and T. Mukai: Scr. Mater. 55 (2006) 593596.

129) C.J. Boehlert: J. Mater. Sci. 42 (2007) 3675-3684.

130) S. Wei, T. Zhu, M. Hodgson and W. Gao: Mater. Sci. Eng. A 550 
(2012) 199-205.

131) X. Zeng, Y. Liu, W. Huang, G. Zeng and G. Zhou: Mater. Sci. Eng. A 571 (2013) 150-154.

132) B. Langelier, A.M. Nasiri, S.Y. Lee, M.A. Gharghouri and S. Esmaeili: Mater. Sci. Eng. A 620 (2015) 76-84.

133) Y. Du, M. Zheng, X. Qiao, D. Wang, W. Peng, K. Wu and B. Jiang: Mater. Sci. Eng. A 656 (2016) 67-74

134) Q. Kang, H. Jiang, Y. Zhang, Z. Xu, H. Li and Z. Xia: J. Alloy. Compd. 742 (2018) 1019-1030.

135) S. Wei, T. Zhu, M. Hodgson and W. Gao: Mater. Sci. Eng. A 585 (2013) 139-148.

136) H. Somekawa, Y. Osawa, A. Singh and T. Mukai: J. Mater. Res. 23 (2008) 1128-1135.

137) B.Q. Shi, R.S. Chen and W. Ke: Mater. Sci. Eng. A 560 (2013) 62-70

138) Z. Li, N. Huang, J. Zhao and S.J. Zhou: Mater. Sci. Technol. 29 (2013) 140-147.

139) Y. Qiao, X. Wang, Z. Liu and E. Wang: Mater. Sci. Eng. A 568 (2013) 202-205.

140) M. Shanthi, P. Jayaramanavar, V. Vyas, D.V.S. Seenivasan and M. Gupta: J. Alloy. Compd. 513 (2012) 202-207.

141) J. Herenguel and P. Lacombe: Metaux 11 (1936) 185-194.

142) J.A. Chapman and D.V. Wilson: J. Inst. Metals 91 (1962-1963) 3940.

143) D.V. Wilson: J. Inst. Metals 98 (1970) 133-143.

144) Z. Yu, A. Tang, J. He, Z. Gao, J. She, J. Liu and F. Pan: Mater. Charact. 136 (2018) 310-317.

145) L. Zhong, J. Peng, M. Li, Y. Wang, Y. Lu and F. Pan: J. Alloy. Compd.
661 (2016) 402-410.

146) J. Bohlen, S. Yi, D. Letzig and K.U. Kainer: Mater. Sci. Eng. A 527 (2010) 7092-7098.

147) K. Suzuki, Y. Chino, X. Huang, M. Yuasa and M. Mabuchi: Mater. Trans. 54 (2013) 392-398.

148) H. Somekawa, D.A. Basha and A. Singh: Mater. Sci. Eng. A 730 (2018) 355-362.

149) H. Somekawa, A. Kinoshita and A. Kato: Mater. Sci. Eng. A 697 (2017) 217-223.

150) Z. Yu, A. Tang, Q. Wang, Z. Gao, J. He, J. She, K. Song and F. Pan: Mater. Sci. Eng. A 648 (2015) 202-207.

151) D.V. Wilson and J.A. Chapman: Philos. Mag. 8 (1963) 1543-1551.

152) N. Ono, R. Nowak and S. Miura: Mater. Lett. 58 (2004) 39-43.

153) J.A. Sharon, Y. Zhang, F. Mompiou, M. Legros and K.J. Hemker: Scr. Mater. 75 (2014) 10-13.

154) Y. Li and M. Enoki: Mater. Trans. 48 (2007) 1215-1220.

155) C.H. Cáceres and A.H. Blake: Mater. Sci. Eng. A 462 (2007) 193196.

156) F.E. Hauser, P.R. Landon and J.E. Dorn: AIME Trans. 206 (1956) 589-593.

157) G.S. Rao and Y.V.R.K. Prasad: Metall. Mater. Trans. A 13 (1982) 2219-2226.

158) H. Somekawa and T. Mukai: Scr. Mater. 53 (2005) 1059-1064.

159) C.H. Caceres, G.E. Mann and J.R. Griffiths: Metall. Mater. Trans. A 42 (2011) 1950-1959.

160) H.J. Frost and M.F. Ashby: Deformation-mechanism Map, (Pergamon Press, Oxford, 1982). 